\title{
An Epistemic Argument for an Egalitarian Public Sphere
}

\author{
Michael Bennett (it) \\ Utrecht University, the Netherlands \\ Email: m.p.b.bennett@uu.nl
}

(Received 19 February 2020; revised 20 July 2020; accepted 11 August 2020)

\begin{abstract}
The public sphere should be regulated so the distribution of political speech does not correlate with the distribution of income or wealth. A public sphere where people can fund any political speech from their private holdings is epistemically defective. The argument has four steps. First, if political speech is unregulated, the rich predictably contribute a disproportionate share. Second, wealth tends to correlate with substantive political perspectives. Third, greater quantities of speech by the rich can "drown out" the speech of the poor, because of citizens' limited attention span for politics. Finally, the normative problem with all this is that it reduces the diversity of arguments and evidence citizens become familiar with, reducing the quality of their political knowledge. The clearest implication of the argument is in favour of strict contribution limits and/or public funding for formal political campaigns, but it also has implications for more informal aspects of the public sphere.
\end{abstract}

\section{Introduction}

Politics is ultimately a matter of speech acts, but speech on a large scale costs money. Where should this money come from? This article compares two models of how the public sphere should be paid for.

Laissez-faire public sphere: Speakers are free to fund political speech using any money they have available to them in the market economy.

Egalitarian public sphere: Regulations are in place that reduce the correlation between the distribution of political speech and the income or wealth of speakers.

I argue that the laissez-faire public sphere is epistemically defective because the rich will predictably dominate public discussion, reducing the diversity of evidence and argument citizens are exposed to. By remedying this defect, a more egalitarian public sphere will improve the relevant political knowledge of citizens. An egalitarian public sphere can be advanced in many ways, but one obvious application is campaign finance. In contemporary democracies, contributions to campaigns are highly correlated with income or wealth. Limits to how much individuals may donate to political campaigns are indispensable for an egalitarian public sphere.

(c) The Author(s), 2020. Published by Cambridge University Press. This is an Open Access article, distributed under the terms of the Creative Commons Attribution licence (http://creativecommons.org/licenses/by/4.0/), which permits unrestricted re-use, distribution, and reproduction in any medium, provided the original work is properly cited 
This article's main epistemological contribution is to apply epistemology to politics. In the process, it contributes to other philosophical debates. In particular, it demonstrates that the epistemic benefits of (deliberative) diversity are only realised insofar as they engender epistemic diversity within individual minds. The well-known "diversity trumps ability" theorem (Hong and Page 2004) tends to obscure this, but it can be illuminated by thinking about falsification and multiple interpretive frames as social processes. While epistemologists are familiar with the idea that the truth and the significance of propositions can come apart, this basic distinction has been neglected in the traditional epistemic argument for free speech.

My argument for egalitarian regulation has three key premises:

1. The public political sphere should be regulated to improve citizens' politically relevant knowledge.

2. Familiarity with a more diverse range of perspectives would improve citizens' politically relevant knowledge.

3. In a laissez-faire public sphere, the political speech that is actually listened to is skewed towards the perspectives of the rich.

Section 2 discusses the first two premises of the argument, which provide the normative goals for policy. Section 3 reviews the case for a laissez-faire public sphere. The empirical premise for my argument is provided in section 4: in a laissez-faire public sphere, the political speech citizens are actually aware of is skewed towards perspectives favoured by the rich. Section 5 explains why, if this is the case, the goal of increasing citizens' politically relevant knowledge is likely to be better advanced in a more egalitarian public sphere.

\section{Preliminaries}

I start by setting the scene. In the debate about money and politics, epistemic considerations have usually been taken to point in the direction of laissez-faire. Epistemic defences of (some degree of) laissez-faire have been offered by David Estlund (2000) as well as the US Supreme Court, and have recently been prominently revived in the work of Ryan Pevnick (2016a, 2016b).

Defenders of a more egalitarian public sphere, on the other hand, have tended to appeal to other considerations: avoiding corruption (Beitz 1990: 203-5; Christiano 2012: 242-45; Dawood 2015; Pevnick 2016a: 1186), relational egalitarianism (on which see Pevnick 2016b: 73-5), and the intrinsic value of equality of opportunity (Cohen 2001; Rawls 2001: Ch. 45; Dworkin 2002).

Egalitarians should not allow advocates of laissez-faire to retain possession of the epistemic high ground. The primary contribution of this paper is to show how egalitarian conclusions actually arise out of a careful consideration of the problems in the epistemic argument for a laissez-faire public sphere (section 3). An epistemic argument for egalitarianism has the dialectical advantage of operating on the same terrain as the most prominent laissez-faire argument, beating it at its own game.

The normative premise of my argument is relatively weak:

The public political sphere should be regulated to improve citizens' politically relevant knowledge.

It seems reasonable that policy made on the basis of better politically relevant knowledge (or made by legislators elected by more knowledgeable voters) will tend to be more 
substantively just or moral. This proposition will be true whatever the appropriate standards of justice or morality turn out to be, and indeed it is something that can be agreed on by people who favour different conceptions of justice (more on this below). By contrast, considerable moral disagreement can be expected on the intrinsic value of equal opportunity for political influence, the distinct value of relational equality, or the substantive distributive injustices caused by policies favoured by the rich. Advocates of a more egalitarian public sphere have struggled when these controversial moral values are framed as conflicting with the epistemic quality of decisions, as advocates of laissezfaire have argued that they do.

Ultimately, the epistemic argument given here is not necessarily in conflict with other reasons for a more egalitarian public sphere, such as those based on anti-corruption, relational equality or the intrinsic value of equality of opportunity. Nor does it preclude a pluralist approach that would assign some value to each consideration. While one can always devise thought-experiments in which these considerations point in different directions, under realistic conditions they all point in the direction of a more egalitarian public sphere.

While the epistemic case for the egalitarian public sphere has been unfortunately neglected, some hints in this direction can be found in the work of Charles Beitz, Ronald Dworkin and Thomas Christiano, and it may be helpful to distinguish my argument from these three authors.

My argument exhibits the basic structure advocated by Beitz (1990: 209), who writes that if we end up choosing laws to promote equality in political speech, "the explanation would not be that equality of resources has intrinsic or fundamental importance but rather that it serves as a convenient proxy for a more complex criterion that would be excessively difficult to interpret or administer". Beitz leaves the issue here; my contribution is to actually set out the more complex criterion (the diversity of arguments and evidence citizens are familiar with), and to set out a reason for thinking equality would be a good proxy for this criterion (the skewed distribution of sources in the laissez-faire public sphere).

Similarly, Dworkin (2002: 364; 2010: sec. 2) asserts that a more egalitarian public sphere will enhance "democratic discourse", but he never really explains why we should expect this to be the case, beyond a few suggestive remarks about "monopolies" in the "marketplace of ideas". Generally, epistemic considerations in Dworkin's theory tend mainly in the direction of laissez-faire, setting limits on egalitarian reforms which are motivated primarily by the intrinsic importance of equal opportunities for political influence.

The author who has gone furthest in developing an epistemic justification for egalitarianism is Christiano, particularly in his account of how the laissez-faire public sphere leads to a skew towards the perspectives of the rich in the public's sources of political information. However, Christiano (2012: 252) does not fully make the connection to knowledge and diversity, stopping on the thought that the dominance of the rich "implies that an enormous amount of local knowledge fails to make an appearance in the public sphere". Instead, Christiano's primary interest in the dominance of the rich is as a premise in a relational egalitarian argument. ${ }^{1}$

My subject is the political public sphere, which I understand as constituted by political speech. I use the term speech as a synecdoche for all discursive elements of political action: not only face-to-face talk but also newspaper editorials, TV adverts,

\footnotetext{
${ }^{1}$ Specifically, the dominance of the rich "suggests a publicly clear way in which the interests of the great majority of the population are not receiving significant attention in decision making. The interests of most people are not treated as worthy of much consideration" Christiano (2012: 252).
} 
posters, door-to-door campaigning, protest marches etc. My general argument applies to both formal political campaigns (whether for elections or referenda), and the informal public sphere. However, there are some differences. The visibility of formal campaigns (and the problems with financing them) should not tempt us to exaggerate their importance compared with the informal public sphere when it comes to forming citizens' political beliefs (Dryzek 2001). However, the nature of formal political campaigns makes them an easier target for regulation than the informal public sphere. Several issues around money in politics are quite specific to the context of formal campaigns.

Importantly for what follows, I understand donations of money to campaigning organisations as a form of indirect or delegated speech, since donors provide others the financial resources to speak on their behalf. In this respect I follow both Estlund (2000) and the US Supreme Court in Buckley v. Valeo (1976). This should not be seen as an admission that epistemic arguments are side-constrained by free-speech considerations, since epistemic considerations themselves are important in justifying free speech protections (Dworkin 2002, 2010).

Within this general category of speech, my subject is further refined to what I call persuasive speech: speech that honestly attempts to change audiences' beliefs. This excludes political speech with other goals, such as deliberate deception or motivating voters to act on beliefs they already have. Despite the fact that these other types of speech are particularly prevalent in formal political campaigns, the normative literature on campaign finance has focused almost exclusively on persuasive speech. This perhaps derives from an assumption that there is no unproblematic way to distinguish persuasion from motivation or deception in particular cases. In my case, the idealising assumption of persuasive speech is a deliberate concession to the laissez-faire argument. Since persuasive speech is the terrain most favourable to the laissez-faire argument, my argument will be all the more significant if it succeeds.

\section{Knowledge and diversity as goals for regulation}

With this background in place, I begin with the normative premise of my argument:

The political public sphere should be structured to increase citizens' politically relevant knowledge.

That is, decisions about whether or how to regulate the public sphere should be guided by the goal of increasing this knowledge. As I indicated, this does not necessarily preclude other moral considerations from playing some role. Rather than entering into an argument about the relative importance of different considerations, I simply claim that the epistemic dimension is a very important consideration, and that it points in an egalitarian direction. In the previous section we saw that the ultimate grounding for my normative premise is that better informed decisions tend to be more substantively just. The normative component here is deliberately thin; unpacking this idea and its implications is chiefly a matter of epistemology.

Ultimately, the kind of knowledge we want citizens to possess is knowledge about how they should act politically - most obviously, how they should vote. ${ }^{2}$ However, I will not appeal directly to prior beliefs about which policies and parties citizens should

\footnotetext{
${ }^{2}$ What I call "politically relevant knowledge" is thus very different from what political scientists normally call "political knowledge". The latter refers specifically to knowledge of uncontroversial facts about the political process such as who the incumbents are, what parties they belong to etc.
} 
favour. Instead, I impose a constraint of impartiality on my theorising. This constraint means that in evaluating the comparative merits of the laissez-faire and egalitarian public spheres I avoid appealing to any substantive conception of justice or the desirability of any particular policy agenda. This constraint of impartiality in constitutional design can be justified in several ways. It might be justified morally, on the basis that respecting others requires settling political disputes with them in a neutral way which is not slanted towards one side or another (e.g. Estlund 2009). Alternatively, impartiality in constitutional design might be justified more pragmatically on the basis that since the function of a political system is to deal with disagreement, it would fail to do so effectively if it were designed to favour one side or the other (e.g. Gerlsbeck 2018). Finally, setting aside any more general considerations in democratic theory, one might simply take it as a dialectical advantage for this particular argument to be free from any commitments to controversial theories of justice.

The impartiality constraint rules out directly assessing people's knowledge about how they should act politically. However, we can nonetheless identify factors that tend to help people acquire knowledge about what they should do politically. For example, people tend to reach better political judgements the more time they spend pondering the issues before them. Unfortunately this does not take us very far in thinking about how political speech is paid for, since there is little reason to think that merely changing the way it is paid for will have much effect on the amount of time people devote to politics (Somin 2013: 185-8). ${ }^{3}$

This article focuses on a different factor: making the time voters do spend acquiring political knowledge more effective. I claim that, other things being equal, familiarity with a more diverse set of relevant arguments and evidence increases citizens' relevant political knowledge. This claim draws support from two different types of theorising: firstly on the epistemic benefits of diversity, and secondly on the importance of falsification.

Examples can help to illustrate each of these ideas. Imagine two people who each spend the same amount of time hearing from others about their life experiences. However, one of them almost exclusively talks with people who share the same social class. The other deliberately tries to talk with people who have a wide range of life experiences. Or, imagine two people who spend the same amount of time studying economics. One of them concentrates exclusively on Marxist economics, while the other spends equal time on neo-classical, Austrian, Keynesian and Marxist schools of thought. Recall that the impartiality constraint rules out any preliminary conclusions about whose life experiences are most relevant to public policy or which school of economics is superior. Given this, my claim about exposure to a diversity of arguments and evidence implies that those who learn about a wider range of life experiences or economic schools of thought are more likely to acquire knowledge which will help them make political decisions. Motivating this conclusion is that for reasoning of this kind, it is particularly important to be able to compare a range of different hypotheses. The value of familiarity with a range of lived experiences or traditions of thought lies in being able to examine the world through a variety of theoretical frames. The diversity which ultimately produces epistemic benefits here is the diversity of perspectives within the mind of one person.

Moving onto falsification, imagine two voters deciding whether the Blue or Red party candidates would be best for the common good. The first voter is only exposed

\footnotetext{
${ }^{3}$ One way to increase the time voters devote to politics would be to reduce the number of voters by lottery, making their individual contributions more salient to the outcome (López-Guerra 2011; Guerrero 2014).
} 
to pro-Blue sources, and develops a detailed knowledge of the strengths of the Blue candidate and the weaknesses of the Red candidate. The second voter is exposed to a variety of sources, and comes to know something about the strengths and weaknesses of each candidate. Again, without knowing anything ourselves about the merits of the candidates, we should expect that the second voter is more likely to reach a good judgement. Notice that this conclusion does not require any deception or falsehood: the beliefs that the first voter acquires from pro-Blue sources might be scrupulously accurate in themselves. What makes the example interesting is precisely that the sheer quantity of true beliefs held by our two voters does not exhaust the question of how knowledgeable they are on the crucial question of which candidate is superior. Indeed, the first voter might actually have a higher "quantity" of true beliefs on the subject (perhaps they spent twice as much time researching), and yet we would nonetheless say the second voter is likely to be more knowledgeable where it counts. This second example does not seem to be so well described as a case where it helps to be able to deploy a range of interpretive frames. Instead, our conclusion seems to be motivated by something more basic: the importance of attending to sources that might falsify one's starting hypothesis rather than only attending to sources which tend to confirm it.

These examples make clear that diversity within the public sphere is not enough. What really matters is diversity within each person's head - that a variety of arguments and evidence is available in their internal processes of belief-formation and decisionmaking. This claim may seem surprising, so it is worth briefly relating it to the literature on diversity, deliberation and epistemic democracy. Democracy is supposed to produce epistemically superior decisions through two mechanisms: counting (aggregative) and talking (deliberative) (Landemore 2013; Vermeule 2013). The former refers to models such as the Condorcet Jury Theorem, which work by using the law of large numbers to cancel out random errors. The latter refers to the sharing and joint production of knowledge. My focus here is on deliberative mechanisms. With this focus, the only way diversity (and indeed deliberation in general) can ultimately improve outcomes is by improving the knowledge of those who finally take decisions.

This is easy to miss when looking at Hong and Page's (2004) famous "diversity trumps ability" model. Although presented as a model of group decision-making, it is not necessary to their model that the deliberating group makes the final decision at all. The group could just as well represent one autocrat and their counsellors. The question never arises because Hong and Page assume unanimous agreement on final decisions. This derives from the prior assumption that all group members instantly recognise a superior solution when they see one: effectively, any group member effortlessly acquires the relevant knowledge of all group members. Thus, when it comes to making decisions, Hong and Page's model makes no distinction between "diversity in the room" and "diversity within the mind of the decision-makers". But when these things come apart, as they will in real politics, voting choices will be determined by what is in the mind of each voter. Diversity in the room only impacts on final decisions via impacting the beliefs of each voter.

In summary, we should endorse Beitz's statement that what we should care about when it comes to campaign finance is the ability of all views to get a decent hearing (1990: 213). Moreover, whether it was Beitz's intended meaning or not, we should emphasise that a variety of views need to be heard - not merely spoken.

Affirming the epistemic value of diversity in politics naturally raises questions about how much diversity is too much. After all, people could increase the diversity of frames available to them (and seek to falsify their prior beliefs) by learning about 
long-abandoned pseudoscience and folklore. ${ }^{4}$ If there is a trade-off between becoming more familiar with the most plausible perspectives and becoming familiar with a wider range of perspectives, there must be some point at which the former is more epistemically beneficial than the latter. It would thus be unwise to think that the epistemic benefits of diversity apply with too much generality.

However, within the specific context of politics, the claim that more diversity would be epistemically beneficial remains very plausible, because the mechanisms motivating it seem particularly important. First, politics is a sphere where abductive reasoning is particularly important, where one tries to infer the best explanations from sets of evidence which are both vast and incomplete. For this type of reasoning, exemplified by the economics example, a diversity of interpretive frames is particularly important. Second, politics is a sphere in which people are particularly susceptible to confirmation bias. This makes it especially important for people to attend to a variety of sources so as to be more likely to encounter information that falsifies their starting hypotheses (Heath 2015: Ch. 5). Our natural cognitive biases push us towards a sub-optimally low level of diversity in the arguments and evidence we pay attention to. This suggests that we should structure our public sphere to lean against these natural biases: my proposals here are just one way of doing so. My argument in sections 4 and 5 relies only on the claim that from where we stand now, it would be epistemically beneficial for citizens to be aware of a more diverse set of relevant arguments and evidence. Moreover, this need not apply generally so long as it applies specifically to topics where people's perspectives are influenced by their socio-economic status.

My normative premise is that the public sphere should be regulated with the goal of realising these potential epistemic gains through diversity. Having set this out, I now turn to an alternative argument that relies on similar epistemic premises.

\section{The case for the laissez-faire public sphere}

This section reconstructs the case for the laissez-faire public sphere. Arguments along these lines have been put forward by Pevnick and Estlund; both offer more nuanced versions of the basic logic deployed by the US Supreme Court. I will take Pevnick as the best representative of this view, since he focuses on the core of the positive argument for laissez-faire, whereas Estlund's proposal is more intricate and idiosyncratic.

According to Pevnick, "the same Millian argument that underlies the ordinary commitment to freedom of speech also provides presumptive reason to worry about prohibitions on campaign-related spending". More speech (more resources devoted to campaigning) is always epistemically valuable. ${ }^{5}$ Of course, the idea cannot be that each individual additional speech act is always epistemically valuable. Even setting aside deliberate deception, some propositions turn out in the end to be false. So, the idea must be more subtle: each additional speech act probabilistically tends to be epistemically beneficial (or, better, each speech act has a positive expected epistemic value). Hence the relevance of a Millian competition of ideas: so long as everybody can speak,

\footnotetext{
${ }^{4}$ More sympathetically, cf. J.S. Mill (1989: 45): "The loss of so important an aid to the intelligent and living apprehension of a truth, as is afforded by the necessity of explaining it to, or defending it against, opponents, though not sufficient to outweigh, is no trifling drawback from the benefit of its universal recognition. Where this advantage can no longer be had, I confess I should like to see the teachers of mankind endeavouring to provide a substitute for it; some contrivance for making the difficulties of the question as present to the learner's consciousness, as if they were pressed upon him by a dissentient champion, eager for his conversion."

${ }^{5}$ Estlund (2000), Cohen (2001) and Dworkin (2002) interpret Buckley v. Valeo (1976) as making the same argument.
} 
additional speech will tend to be epistemically positive because false or misleading speech will be rooted out and exposed by other speakers. This closely corresponds to the falsification argument for diversity that I gave in the previous section.

Pevnick's distinctive addition to this traditional argument is to point out that large amounts of money are necessary to propagate ideas in mass politics. Broadcasting a message (for example in a radio advert) only once is unlikely to reach many people. The same message must be broadcast again and again to make it likely that a significant number of people actually hear it. Thus, seemingly repetitive speech which brings no new ideas to the public sphere in general may nonetheless bring new ideas to additional individuals who hear it each time. And it is this repetition that costs lots of money.

Pevnick's approach is summarised in his comment on Ross Perot, a US billionaire who paid for his own presidential campaigns in 1992 and 1996:

Citizens persuaded by Perot had the opportunity to vote for a candidate raising issues and concerns not being discussed by others. Meanwhile, citizens who rejected Perot's case remained free to vote for other candidates, but were at least exposed to an ardent advocate of a competing perspective. The Millian proposition is that, in at least one important sense, both sets of voters were better off because of Perot's willingness to spend part of his fortune on political speech. (Pevnick 2016b: 59)

Pevnick is keen to qualify his argument as establishing only a "presumption" against restrictions, meaning,

it picks out one important epistemic concern. There are, of course, other important considerations, and even competing epistemic considerations (such as concerns about the distribution of resources devoted to different views) ... I simply seek to show that the prohibitions needed to instantiate EOPI [equal opportunity for political influence] have one important type of cost that needs to be taken into account in any prescriptive discussion of campaign finance. (Pevnick 2016b: 58)

However, even this cautious formulation is mistaken. More speech does not always generate greater voter awareness of different arguments and evidence. Under some circumstances, more speech can actually reduce voters' awareness of different arguments and evidence: it has negative expected epistemic value. Under such circumstances, prohibitions on private spending do not carry the epistemic cost Pevnick asserts at all. This article identifies one set of circumstances in which this is the case.

The crucial mistake here (not one limited to Pevnick) is aggregating "political speech" as a homogeneous good. Treated like an economic commodity in this way, it seems clear that, other things being equal, more is better. When we proceed more carefully and examine how political speech can be disaggregated, this assumption is unwarranted. This is the kind of analysis I will undertake in the next section.

The laissez-faire public sphere has a second line of defence: a denial that political speech can be disaggregated without creating unacceptable dangers of manipulation and corruption. Certainly, any direct attempt by the state to differentiate between epistemically valuable or harmful speech would be highly problematic and liable to abuse by incumbent officeholders. But that is not what is being envisaged here. Instead, we can identify very general scenarios in which speech is likely to be epistemically harmful and regulate these. Restrictions on speech should be content- or viewpoint-neutral, and should not allow legislators or bureaucrats to treat speech differently on the basis of its actual content. Prohibitions on private donations to political campaigns do not have 
this feature: they do not involve the state in any judgement about the worth of the actual content being communicated. Of course, the details of any scheme of regulation and public funding will have to be carefully interrogated for any accountability concerns. Although Pevnick focuses on the funding of formal campaigns, he too is keen to generalise to the informal public sphere; the same goes for my critique.

\section{The dominance of the rich in the laissez-faire public sphere}

I now proceed to the substance of that critique. This section explains the problem with the laissez-faire public sphere. In a laissez-faire public sphere, the set of arguments and evidence citizens are familiar with will be skewed towards perspectives favoured by the rich. This is the first step of my argument for egalitarian regulations; the second step will be considered in the following section. The first step goes as follows:

1. Political speech (insofar as it is actually listened to) is subject to scarcity.

2. In a laissez-faire public sphere, the rich contribute a disproportionate share of speech.

\section{Therefore}

3. In a laissez-faire public sphere, the political speech that is actually listened to is skewed towards the perspectives of the rich.

The key premise here is that political speech is subject to scarcity, such that more speech from one party can "drown out" speech from another. This point has been well argued by Christiano (2012: 248-9). On the face of it, "drowning out" seems like an odd claim. Especially since the development of the internet, there is no "message scarcity": you can always get your message out somewhere, and there are no technical barriers to it being read by almost unlimited numbers of people. There is, however, "cognitive scarcity" in the amount of attention individuals devote to an issue. In response to this cognitive scarcity, the media industry has created well-packaged, easily digestible sources of news and opinion, and it is rational for individuals to get their political information from these sources. It is in these crucial packaged information sources that the perspectives of the poor are (relatively) drowned out. There will always be space on the internet, but the number of pages in The Sun, the number of hours Fox News broadcasts in a day, and even the amount of stories on the Buzzfeed front page are limited. Of course, The Sun could always decide to add additional pages to the paper, Fox could add more channels, and Buzzfeed could add more stories to the front page. Ultimately however, the space for reaching people remains limited; increasing the size of a publication like The Sun would merely reduce the average number of viewers for each item within it, or even put viewers off that particular publication altogether.

Christiano's point can be seen most clearly in the controlled context of formal political campaigns. Consider what happens when total spending on a campaign goes up say from one to two billion dollars. Even though the amount of resources devoted to campaigning has doubled, it's highly unlikely that the amount of time voters spend thinking about the election will increase at all, let alone double. In the USA, for example, campaign spending has dramatically and continually increased while turnout has remained relatively constant since the early twentieth century. So, if voters are spending the same amount of time thinking about politics, where will that extra billion dollars go? We might think of the situation as akin to a market in which the demand for political attention has doubled while the supply of political attention is inelastic. 
The predictable consequence is that all the extra money spent campaigning will merely bid up the metaphorical "price" of attention. This might happen in two ways. The candidates might spend their money making their campaigns slicker - more likely to attract voters' attention relative to other uses of time, or their competitors' campaigns. The price of attention can also be bid up in a more literal fashion. Owners of billboards, television stations and newspapers effectively control a certain slice of public attention that they can sell to the highest bidder. Increasing aggregate political spending will literally bid up the price of public attention by bidding up the price of advertising space. ${ }^{6}$ Additional political speech can have the effect of drowning out the speech of others by bidding up the price of political attention to a level only the rich can afford.

If everyone contributed equally to political debate, it would not be an epistemic problem that the political speech that is actually attended to is subject to scarcity. A problem arises when certain groups have a higher tendency to speak than others, and when these differences also correlate with substantive differences in political perspectives. Richer people contribute to political campaigns far out of proportion to their numbers (Center for Responsive Politics 2016; Electoral Commission 2019; see below for discussion). In the first place, this is simply because richer people have more money than other people to spend on campaign donations, just like everything else. In the second place, it's because spending on politics is a "superior good", the demand for which tends to increase disproportionately as people become more affluent. When scarce access to public attention is effectively rationed by a market mechanism, it shouldn't be surprising that this access is disproportionately purchased by the wealthy.

Compared to formal political campaigns, drowning-out is harder to establish when it comes to the informal public sphere. One section of the public sphere, including thinktanks, campaigning groups and lobbyists, is primarily funded by voluntary donations. The audience for such organisations is usually legislators and regulators directly, rather than voters. Donor-funded organisations of these kinds are subject to the same dynamic that was discussed in the previous paragraph for formal political campaigns. Their funding tends to be dominated by the rich, for similar reasons. ${ }^{7}$

However, another section of the public sphere, including newspapers, TV stations and other media, is primarily funded by audience subscriptions and advertising revenue. This section of the public sphere is forced by the discipline of the market to cater to the preferences of audiences rather than those of donors, and so is not subject to the same dynamic as political campaigns.

Nonetheless, even for these non-donation-funded parts of the informal public sphere, there are three mechanisms that might cause the rich to contribute a disproportionate share of political speech. First, advertisers (in the aggregate) target not merely the largest audiences, but the wealthiest audiences. Insofar as media firms seek advertising revenue, they are therefore incentivised to cater to the preferences of wealthier audiences in particular, even though their media products are also consumed by poorer audiences.

Second, media workers disproportionately come from privileged social origins. In the UK, $36 \%$ of journalists had parents who were higher managers and professionals

\footnotetext{
${ }^{6}$ A striking observation of this was provided by Michael Bloomberg's 2020 US Democratic Party presidential primary campaign (King 2020). To my knowledge, the topic has not been seriously investigated by social scientists. Fowler and Ridout (2010:5) speculate that increased demand for political advertising space on TV could explain why both the price and the volume of political ads has increased in the USA.

${ }^{7}$ The extent to which think tanks rely on wealthy individuals and companies for funding is documented for the USA by Medvetz (2012) and Domhoff (2014), for Canada by McLevey (2014) and for Spain by Parrilla et al. (2016).
} 
(as opposed to $9 \%$ of the general population), while only $8 \%$ had parents from routine and semi-routine occupations (as opposed to $37 \%$ of the general population) (Friedman et al. 2015: 273; see also Spilsbury 2018; Sutton Trust and Social Mobility Commission 2019). In the USA, journalists at the New York Times and Wall Street Journal were around 50 times more likely to have attended an elite university than the general population (Wai and Perina 2018). Journalists around the world are more likely to be male and university educated (Willnat et al. 2013), while journalists in the USA and UK are less likely to come from ethnic minorities (Spilsbury 2018; Weaver et al. 2019). The intrinsic desirability of media jobs renders them highly competitive. Employers can demand high quantities of cultural and social capital. Those who possess this capital tend to come from rich backgrounds. Furthermore, employers can also demand years of unpaid internships or insecure freelance work. This similarly filters out candidates from poorer backgrounds.

Third, media ownership in most countries is highly concentrated. Studying 13 countries, Eli Noam and his collaborators (2016: 8) found that on average the top four companies accounted for $67 \%$ of the market for media content generation (distribution platforms were even more concentrated). Media content companies are also unusually likely to be controlled by individuals or families (rather than a wide base of shareholders). In a study of 97 countries, Djankov et al. (2003: 357) found that 57\% of newspapers and $34 \%$ of TV stations were controlled by families. Putting content and platforms together, Noam and The International Media Concentration Collaboration (2016: 1197) estimated somewhere between 8 and 16\% of the global media market was owned by just 30 individuals.

How strongly the second and third mechanisms operate depends very much on whether market discipline forces media outlets to cater to the pre-existing political preferences of their audiences, or whether media workers and owners have some slack to produce content that reflects their own political perspectives. Furthermore, some media owners may simply be willing to subsidise the promotion of their political views, accepting lower profits as the cost of doing so. An interesting example is the Sinclair Broadcast Group, which has been buying local TV stations in the USA, sharply slanting their coverage to the ideological right, and apparently suffering a slight decrease in viewership as a result (Matthews 2018). I will not attempt to pronounce on these issues here, although they will obviously affect the strength of the argument we will be left with.

One might object that the picture painted above is increasingly disrupted by new internet technologies. For the reasons given, it seems unlikely the internet has significantly increased the amount of time people spend on politics. More plausible is that the media is becoming increasingly segmented along ideological lines. "Filter bubbles" of this kind of course raise their own challenge to epistemic diversity. However, there is no necessary reason to think that increased segmentation would mitigate the pro-rich mechanism identified above, which may continue to apply within each of the more segmented media subsystems. Moreover, while some novel forms of online propaganda have been funded by foreign governments, others (such as the activities of Cambridge Analytica) have been funded by wealthy individuals, and so remain subject to the same pro-rich skew described above (Cadwalladr and Graham-Harrison 2018). Finally, we should remember that while the trend is certainly towards online media, there is still a long way to go. For example, in a 2019 survey, 65\% of UK respondents and $63 \%$ of US respondents reported that their first contact with the day's news was from an offline source (Newman 2019: 16).

Cognitive scarcity means that the non-wealthy find it more difficult to pay for the prime real-estate of public attention. Coupled with the correlation between wealth 
and substantive political perspectives, this means that audiences in the laissez-faire public sphere will pay attention to a set of sources that are skewed towards the perspectives favoured by the rich.

\section{Equality as a contributor to diversity}

In the previous section, I argued that:

In a laissez-faire public sphere, the political speech that is actually listened to is skewed towards the perspectives of the rich.

The final step of my argument is that this leads audiences towards a less diverse set of relevant arguments and evidence, reducing citizens' relevant political knowledge. Because the arguments and evidence people are exposed to derive disproportionately from the rich, people are exposed to a less diverse set of arguments and evidence.

The pro-rich skew reduces diversity because being rich tends to go along with a particular ideology: the income or wealth of speakers makes a significant difference to the content of what is spoken. Income and wealth are excellent predictors of party political affiliation and of stances on a whole host of issues. ${ }^{8}$ This kind of skew in the set of perspectives that are publicly represented is an important one, because the kinds of class-based issues that correlate most closely with income are among the most important political issues in contemporary democracies.

Moreover, the rich who fund campaigns are also relatively homogeneous simply because they are a fairly small group. The 10 largest individual donors accounted for $6 \%$ of all campaign donations in the USA in the 2016 cycle (Center for Responsive Politics 2016). Of course, the USA is an exceptional case. But in the UK, where the amount spent on campaigning per voter was 20 times lower, the top 1163 registered donors still accounted for half of all private funding for political parties in 2017. ${ }^{9}$ As a matter of raw numbers, groups of this size will be less cognitively diverse than the population as a whole. Moreover, wealth is also highly correlated with certain other characteristics, such as race, gender and occupation, leading rich donors to be much more homogeneous than a randomly selected group of the same size.

There is no suggestion here of quid-pro-quo corruption, of donors expecting to receive favours from politicians in return for their contributions (that would be a separate, normatively simpler issue). Donors might be motivated solely by moral considerations and seeking to advance the common good as they see it. The concern is not with their intentions. The problem is with the consequence: that the kinds of arguments and evidence that tend to be put forward by wealthier people drown out the kinds of arguments and evidence that tend to be put forward by poorer people. The correlation of riches and perspectives is consistent with thinking that people vote for the common good rather than for personal interest: it simply implies that their political beliefs tend to be skewed in favour of people like them. ${ }^{10}$

\footnotetext{
${ }^{8}$ This has been documented many times; Peterson (2016) is one recent example.

${ }^{9}$ This statistic is compiled from the UK Electoral Commission's (2019) public database, available at http://search.electoralcommission.org.uk.

${ }^{10} \mathrm{Cf}$. Madison (1987): "As long as the reason of man continues fallible, and he is at liberty to exercise it, different opinions will be formed. As long as the connection subsists between his reason and his self-love, his opinions and his passions will have a reciprocal influence on each other; and the former will be objects to which the latter will attach themselves." That most voting is oriented towards the common good (as the voter sees it) is agreed by contemporary critics of democracy (Caplan 2011; Somin 2013; Brennan 2016).
} 
The pro-rich skew can operate in practice along a spectrum from the most general level of ideology to the most specific level of factual details. At the general level of ideology, audiences will tend to become more familiar with the broad outlines of ideologies favoured by the rich. For example, people might become familiar with arguments about the value of individual freedom or the causal influence of hard work, neglecting arguments about the value of distributive equality or the causal influence of social structures. This corresponds to the examples I gave in section 2 of people who are only exposed to one type of economic theory, or only interact with members of one social class.

At the specific level of factual detail, audiences will tend to become familiar with the virtues of pro-rich candidates and the vices of anti-rich candidates. This was the example presented in section 2 featuring the Red and Blue parties. For example, audiences will tend to learn more from adverts about the unpopular stances taken by anti-rich candidates, relative to what they learn about the unpopular stances taken by pro-rich candidates. Between these general ideological frameworks and specific factual details there are a variety of ways bias can creep in, for example in people's relative familiarity with arguments about the merits and the disadvantages of particular policies.

Once again, it should be emphasised that the quantity of true beliefs people have can come apart from the kind of relevant political knowledge that we want to promote. In a well-resourced laissez-faire public sphere, audiences may have a greater quantity of true beliefs about politics than an egalitarian public sphere. But if the sources for these beliefs are less diverse, the quality of their relevant political knowledge will be lower. Under these conditions the speech of the rich in the laissez-faire public sphere has a negative epistemic impact in absolute terms. This is not because these speech acts are misleading in themselves, but because they are misleading when placed in the broader context of a skewed distribution of speech. In another situation, the same speech-act might be epistemically valuable. Even if measures to create a more egalitarian public sphere reduced the total quantity of political speech, this would still increase epistemic value, because audiences would become familiar with a more diverse range of arguments and evidence.

To sum up: due to the pro-rich skew in the public sphere, audiences will predominantly be exposed to those ideologies and those facts which rich donors wish to broadcast. Consequently, audiences will attend to a less diverse set of arguments and evidence. On the other hand, in a more egalitarian public sphere, audiences would hear perspectives favoured by people of different levels of income and wealth. Consequently, audiences in a more egalitarian public sphere would attend to a more diverse set of arguments and evidence.

The egalitarian public sphere is a way of framing "equal opportunities" for political influence or political speech. ${ }^{11}$ To give content to the idea of equal opportunities, one must specify which factors are taken to be legitimately relevant or not in influencing the outcome. My definition of the egalitarian public sphere focuses on income and wealth as illegitimate influences on the distribution of political speech (not merely as it is spoken, but as it is listened to). I choose this framing to focus our minds away from equality of opportunity for speech at the individual level and towards inegalitarian tendencies we observe in the public sphere as a whole, which can be shifted with public policy.

Before concluding, it may be helpful to briefly set out some of the concrete ways the abstract goal of an egalitarian public sphere might be advanced. Beitz draws a distinction between strategies of redistribution and strategies of insulation (Beitz 1990: 193;

\footnotetext{
${ }^{11}$ All the commentators cited here are keen to stress that, due to the epistemic element of speech, equality of actual influence would be an inappropriate goal. On this point see in particular Ortiz (1998).
} 
cf. Machin 2012). Strategies of redistribution cut the Gordian knot of money in politics by simply reducing economic inequality itself. The epistemic argument against money in politics simply functions as an additional consideration in favour of distributive equality.

Strategies of insulation instead seek to reduce the influence money has on politics and political speech. Insulation is necessarily more complex, and requires greater elaboration.

Insulation is easiest to achieve in the formal context of election campaigns. My argument here has provided a basis for limiting the amount of money citizens can contribute to political campaigns, even where such limits reduce net spending on campaigning. However, contribution limits should also be accompanied with some manner of public funding. Even in the absence of contribution limits, public funding can still function positively to increase the representation of perspectives not favoured by the rich. ${ }^{12}$

In aiming to eliminate the differential influence of money, I take no further stance on what should or should not influence who speaks and who is listened to. In particular, an egalitarian public sphere as I define it is consistent with a variety of principles for funding political campaigns. It is compatible with ensuring that all credible candidates have (only) the same amount of public funding. ${ }^{13}$ But it is also compatible with systems under which candidates with greater public support enjoy greater funds.

In the ordinary course of politics and in the broader public sphere, insulation is much more difficult to achieve. However, there are still measures worth considering. Insofar as wealthy media proprietors influence the content their organisations produce, this is a reason to legislate against the concentration of media ownership. Insofar as media content is influenced by the privileged social backgrounds of its creators, this is a further reason to make it easier for people with less privileged backgrounds to enter media and political careers. There are many ways to attempt this, but a start would be to make it harder for media and political organisations to employ unpaid interns.

An important subset of insulation strategies work through compensation: creating an egalitarian distribution not by reducing the speech of the over-represented, but by increasing the speech of the under-represented. This is particularly important in the informal public sphere, where restrictions are more likely to raise concerns about expressive elements of free speech (Christiano 2012: 255).

Traditional publicly funded discursive institutions such as state broadcasters and public universities could be interpreted as performing a compensatory role of this kind through their mission to promote a balanced debate. My argument accordingly offers some support to such institutions. It also gives institutions like universities reason to be more leery of accepting private donations that come with ideological strings attached.

In addition, we might seek new ways of subsidising the speech of the poor through voucher schemes, as Christiano (2012: 255) suggests. Christiano does not indicate how this might work, but we could take inspiration from schemes recently proposed in reaction to worries about the decline of news journalism. McChesney and Nichols (2016: 259-63), for example, propose giving citizens vouchers which they can bestow on

\footnotetext{
${ }^{12}$ For empirical evidence on the relative efficacy of contribution limits and public funding, see Scarrow (2007).

${ }^{13}$ For critique of which see Pevnick (2019). To be clear, "levelling the playing field" in this sense may not be sufficient for an egalitarian public sphere, because there may be more candidates from wealthy backgrounds. If so, maintaining an egalitarian public sphere would require further policies to encourage more candidates from poorer backgrounds to participate.
} 
non-profit news outlets. ${ }^{14}$ Although their proposal is inspired by a conception of journalism as a public good, it would also have the effect of giving poorer citizens more influence over journalistic content. This type of proposal could be extended beyond reporting to cover the kind of advocacy and analysis currently provided mainly by donor-funded organisations.

\section{Conclusion}

This paper has set out an epistemic argument in favour of an egalitarian public sphere, regulated such that the distribution of political speech is independent of the distribution of income or wealth. The normative premise of this argument was that the design of the political system should promote the relevant knowledge of political decision-makers. This directs us to promote the diversity of arguments and evidence voters are exposed to. I argued that under realistic circumstances we can best do so by creating a more egalitarian public sphere, removing some of the differential influence of money in politics.

The argument for an egalitarian public sphere that I have presented is limited in several ways, some of which could helpfully be clarified by further empirical work in the future. There are three core premises on which the argument could be challenged:

1. Wealth or income correlates with differences in substantive political perspectives.

2. The rich contribute a disproportionate share of political speech compared to the poor.

3. Political speech is subject to scarcity, such that more speech by some can drown out others.

For the sake of simplicity, I have presented these three premises as conditions, but it would be more accurate to view them as continuous variables. The values of these variables determine the strength of the case for egalitarian regulations. Thus, the argument for a more egalitarianism public sphere is stronger the more the rich contribute compared with the poor, the more riches correlate with substantive perspectives, and the more political speech is subject to scarcity.

The first premise is relatively uncontroversial, and the second is also well established for the case of formal political campaigns. It is harder to argue for the second premise for the informal public sphere, because the mechanisms through which the rich contribute more speech than the poor in this context are subtler and harder to measure. The third premise is also easier to establish for formal political campaigns than for the informal public sphere. Formal campaigns are subject to tight time constraints, and voters' attention spans are often very limited.

This suggests that the epistemic case for egalitarian interventions will be easiest for formal political campaigns and harder to make for the informal public sphere. Appropriate empirical research could help to clarify these contested questions. However, we should also be wary of drawing conclusions too quickly from existing research. For example, on standard measures, political ignorance is relatively invariant between different jurisdictions, even when regulations on political speech vary considerably (Caplan 2011; Somin 2013). This might be taken to indicate that political knowledge is overwhelmingly determined by "demand-side" influences, with "supply-side" influences (such as the pro-rich skew discussed in this paper) having little effect. However, this inference would be too quick. Political knowledge is normally measured

\footnotetext{
${ }^{14}$ For an related proposal see Ackerman (2013).
} 
by testing whether respondents know uncontested political facts such as who occupies which political office. Diversity of perspectives was never likely to increase this kind of knowledge (of uncontested facts). Instead, diversity is supposed to increase voters' knowledge of different moral or causal theories for evaluating government, and different considerations for or against different candidates or options - things that political knowledge surveys are less likely to assess. Assessing the strength of the epistemic case for an egalitarian public sphere will thus require different kinds of empirical research, or more creative uses of existing data.

Insofar as this argument has been successful, it provides a practical example of constitutional design within the framework of epistemic democracy. It shows how potentially controversial institutional recommendations can be made using only epistemic considerations which are neutral between different substantive conceptions of justice. Egalitarians should not abandon epistemic considerations to the advocates of laissezfaire. An egalitarian public sphere is an invaluable resource for citizens to find out what they need to know.

\section{References}

Ackerman B. (2013). 'Using the Internet to Save Journalism from the Internet.' In A. Gosseries and P. Vanderborght (eds), Arguing about Justice: Essays for Philippe Van Parijs, pp. 41-47. Louvain-la-Neuve: Presses universitaires de Louvain.

Beitz C.R. (1990). Political Equality: An Essay in Democratic Theory. Princeton, NJ: Princeton University Press.

Brennan J. (2016). Against Democracy. Princeton, NJ: Princeton University Press.

Buckley v. Valeo. (1976). 424 US 1. Supreme Court.

Cadwalladr C. and Graham-Harrison E. (2018). 'Revealed: 50 Million Facebook Profiles Harvested for Cambridge Analytica in Major Data Breach.' The Guardian, 17 March. https:/www.theguardian.com/ news/2018/mar/17/cambridge-analytica-facebook-influence-us-election.

Caplan B. (2011). The Myth of the Rational Voter: Why Democracies Choose Bad Policies. Princeton, NJ: Princeton University Press.

Center for Responsive Politics. (2016). 'Top Individual Contributors: All Federal Contributions.' OpenSecrets. 2016. https://www.opensecrets.org/overview/topindivs.php? cycle=2016\&view=fc.

Christiano T. (2012). 'Money in Politics.' In D. Estlund (ed.), The Oxford Handbook of Political Philosophy, pp. 241-58. Oxford: Oxford University Press.

Cohen J. (2001). 'Money, Politics and Political Equality.' In A. Byrne, R.C. Stalnaker and R. Wedgwood (eds), Fact and Value: Essays on Ethics and Metaphysics for Judith Jarvis Thomson, pp. 47-80. Cambridge, MA: MIT Press.

Dawood Y. (2015). 'Campaign Finance and American Democracy.' Annual Review of Political Science 18(1), 329-48.

Djankov S, McLiesh C., Nenova T. and Shleifer A. (2003). 'Who Owns the Media?' Journal of Law and Economics 46(2), 341-82.

Domhoff G.W. (2014). Who Rules America? The Triumph of the Corporate Rich, 7th edn. Boston, MA: McGraw-Hill.

Dryzek J.S. (2001). 'Legitimacy and Economy in Deliberative Democracy.' Political Theory 29(5), 651-69.

Dworkin R. (2002). 'Free Speech, Politics, and the Dimensions of Democracy.' In Sovereign Virtue: The Theory and Practice of Equality, pp. 351-85. Cambridge, MA: Harvard University Press.

Dworkin R. (2010). 'The Decision that Threatens Democracy.' New York Review of Books, 13 May. http:// www.nybooks.com/articles/archives/2010/may/13/decision-threatens-democracy/.

Electoral Commission. (2019). 'Registers Search Page.' http://search.electoralcommission.org.uk.

Estlund D. (2000). 'Political Quality.' Social Philosophy and Policy 17(1), 127-60.

Estlund D. (2009). Democratic Authority: A Philosophical Framework. Princeton, NJ: Princeton University Press.

Fowler E.F. and Ridout T.N. (2010). 'Advertising Trends in 2010.' The Forum 8(4). https://doi.org/10/ dfqbq6. 
Friedman S., Laurison D. and Miles A. (2015). 'Breaking the 'Class' Ceiling? Social Mobility into Britain's Elite Occupations.' Sociological Review 63(2), 259-89.

Gerlsbeck F. (2018). 'What Is Democratic Reliability? Epistemic Theories of Democracy and the Problem of Reasonable Disagreement.' Critical Review of International Social and Political Philosophy 21(2), 218-41.

Guerrero A.A. (2014). 'Against Elections: The Lottocratic Alternative.' Philosophy \& Public Affairs 42(2), $135-78$.

Heath J. (2015). Enlightenment 2.0: Restoring Sanity to Our Politics, Our Economy, and Our Lives. Toronto: Harper.

Hong L. and Page S.E. (2004). 'Groups of Diverse Problem Solvers Can Outperform Groups of High-Ability Problem Solvers.' Proceedings of the National Academy of Sciences USA 101(46), 16385-9.

King M. (2020). 'Bloomberg's Massive Ad Campaign Hikes TV Prices for Other Candidates.' Politico, 20 January. https://www.politico.com/news/2020/01/20/bloomberg-ad-campaign-hikes-tv-prices-100572.

Landemore H. (2013). Democratic Reason: Politics, Collective Intelligence, and the Rule of the Many. Princeton, NJ: Princeton University Press.

López-Guerra C. (2011). 'The Enfranchisement Lottery.' Politics, Philosophy \& Economics 10(2), 211-33.

Machin DJ. (2012). 'Political Inequality and the 'Super-Rich': Their Money or (Some of) Their Political Rights.' Res Publica 19(2), 121-39.

Madison J. (1987). 'The Federalist No. 10.' In A. Hamilton, J. Madison and J. Jay, The Federalist Papers. London: Penguin Classics.

Matthews D. (2018). 'Sinclair Broadcast Group, the pro-Trump, Conservative Company Taking over Local News, Explained.' Vox, 3 April 3. https://www.vox.com/2018/4/3/17180020/sinclair-broadcast-groupconservative-trump-david-smith-local-news-tv-affiliate.

McChesney R.W. and Nichols J. (2016). People Get Ready: The Fight Against a Jobless Economy and a Citizenless Democracy. New York, NY: Nation Books.

McLevey J. (2014). 'Think Tanks, Funding, and the Politics of Policy Knowledge in Canada.' Canadian Review of Sociology/Revue Canadienne de Sociologie 51(1), 54-75.

Medvetz T. (2012). Think Tanks in America. Chicago, IL: University of Chicago Press.

Mill J.S. (1989). 'On Liberty.' In S. Collini (ed.), On Liberty with The Subjection of Women and Chapters on Socialism. Cambridge: Cambridge University Press.

Newman N. (2019). 'Reuters Institute Digital News Report 2019.' Reuters Institute for the Study of Journalism. http://www.digitalnewsreport.org/.

Noam E.M. and The International Media Concentration Collaboration. (2016). Who Owns the World's Media?: Media Concentration and Ownership around the World. Oxford: Oxford University Press.

Ortiz D.R. (1998). 'The Democratic Paradox of Campaign Finance Reform.' Stanford Law Review 50(3), 893-914.

Parrilla R., Almiron N. and Xifra J. (2016). 'Crisis and Interest: The Political Economy of Think Tanks During the Great Recession.' American Behavioral Scientist 60(3), 340-59.

Peterson E. (2016). 'The Rich Are Different: The Effect of Wealth on Partisanship.' Political Behavior 38(1), 33-54.

Pevnick R. (2016a). 'The Anatomy of Debate about Campaign Finance.' Journal of Politics 78(4), 1184-95.

Pevnick R. (2016b). 'Does the Egalitarian Rationale for Campaign Finance Reform Succeed?' Philosophy \& Public Affairs 44(1), 46-76.

Pevnick R. (2019). 'Should Campaign Finance Reform Aim to Level the Playing Field?' Politics, Philosophy \& Economics 18(4), 358-73.

Rawls J. (2001). Justice as Fairness: A Restatement. Edited by Erin Kelly. Cambridge, MA: Belknap Press.

Scarrow S.E. (2007). 'Political Finance in Comparative Perspective.' Annual Review of Political Science 10(1), 193-210.

Somin I. (2013). Democracy and Political Ignorance: Why Smaller Government is Smarter. Stanford, CA: Stanford University Press.

Spilsbury M. (2018). 'Journalists at Work.' National Council for the Training of Journalists. https://www. nctj.com/downloadlibrary/JaW\%20Report\%202018.pdf.

Sutton Trust and Social Mobility Commission. (2019). 'Elitist Britain 2019.' https://www.suttontrust.com/ our-research/elitist-britain-2019/.

Vermeule A. (2013). 'Collective Wisdom and Institutional Design.' In H. Landemore and J. Elster (eds), Collective Wisdom: Principles and Mechanisms, pp. 338-66. Cambridge: Cambridge University Press.

Wai J. and Perina K. (2018). 'Expertise in Journalism: Factors Shaping a Cognitive and Culturally Elite Profession.' Journal of Expertise 10(10), 21. 
Weaver D.H., Willnat L and Wilhoit G.C. (2019). 'The American Journalist in the Digital Age: Another Look at U.S. News People.' Journalism \& Mass Communication Quarterly 96(1), 101-30.

Willnat L., Weaver D.H. and Choi J. (2013). 'The Global Journalist in the Twenty-First Century.' Journalism Practice 7(2), 163-83.

Michael Bennett is a postdoctoral researcher at Utrecht University, with a $\mathrm{PhD}$ from the University of York. He works on the political theory of markets, democracy and corporate governance. He is particularly interested in how we should understand and regulate the relationship between democracy and capitalism. m.p.b.bennett@uu.nl

Cite this article: Bennett M (2020). An Epistemic Argument for an Egalitarian Public Sphere. Episteme 1-18. https://doi.org/10.1017/epi.2020.42 